Tropical Journal of Pharmaceutical Research August 2017; 16 (8): 1989-1995

ISSN: $1596-5996$ (print); 1596-9827 (electronic)

(C) Pharmacotherapy Group, Faculty of Pharmacy, University of Benin, Benin City, 300001 Nigeria.

All rights reserved.

Available online at http://www.tjpr.org

Original Research Article

http://dx.doi.org/10.4314/tjpr.v16i8.32

\title{
Arabic translation and cultural adaptation of Liverpool Adverse Events Profile (LAEP) among a sample of epileptic older adults
}

\author{
Yazed Sulaiman AIRuthia ${ }^{1 \star}$, Haya Almalaq ${ }^{1}$, Huda Alzahrani ${ }^{1}$, Fawaz \\ Al-hussain ${ }^{2}$, Reem AlGasem ${ }^{3}$ and Lama AlMutairi ${ }^{4}$ \\ ${ }^{1}$ Department of Clinical Pharmacy, College of Pharmacy, King Saud University, Riyadh, Saudi Arabia, ${ }^{2}$ Department of Medicine, \\ Neurology Division, College of Medicine, King Saud University, Riyadh, Saudi Arabia, ${ }^{3}$ Department of Pharmacy, King Faisal \\ Specialist Hospital and Research Center, Riyadh, Saudi Arabia, ${ }^{4}$ Department of Pharmacy, King Abdulaziz University Hospital, \\ Riyadh, Saudi Arabia
}

*For correspondence: Email: yalruthi@gmail.com; Tel: +966114677483; Fax: +966114677480

Sent for review: 17 May 2017

Revised accepted: 26 July 2017

\begin{abstract}
Purpose: To validate and culturally adapt Liverpool Adverse Events Profile (LAEP) in Arabic among a sample of elderly patients with epilepsy.

Methods: The face and content validity of the Arabic version of LAEP was ensured by a group of healthcare professionals. Undemented elderly patients ( $\geq 60$ years) with seizure disorders, who are on a single antiepileptic drug (AED), were recruited from two tertiary care centers in Riyadh, Saudi Arabia. Factor analysis was performed to check the construct validity. The reliability was measured using Cronbach's alpha method.

Results: Seventy-four patients met the inclusion criteria and were interviewed. Most of the participants had generalized seizures $(67.57 \%)$, and were either illiterate or with elementary school education $(62.16 \%)$. Their mean age was 68.9 years, and $51.35 \%$ were male. About two-thirds of the participants were on either carbamazepine or levetiracetam (66.22 \%). Six factors were extracted from the Arabic version of LAEP. Cronbach's alpha of the Arabic version of LAEP was 0.84. The mean overall LAEP score was 28.9.

Conclusion: The Arabic version of LAEP demonstrates good validity and reliability. Similar studies should examine its validity and reliability among different epileptic patient populations.
\end{abstract}

Keywords: Adverse drug event, Epilepsy, Older adults, Cronbach's alpha, Liverpool Adverse Events Profile, Seizure disorders, Carbamazepine, Levetiracetam

Tropical Journal of Pharmaceutical Research is indexed by Science Citation Index (SciSearch), Scopus, International Pharmaceutical Abstract, Chemical Abstracts, Embase, Index Copernicus, EBSCO, African Index Medicus, JournalSeek, Journal Citation Reports/Science Edition, Directory of Open Access Journals (DOAJ), African Journal Online, Bioline International, Open-J-Gate and Pharmacy Abstracts

\section{INTRODUCTION}

Epilepsy is one of the most prevalent neurological disorders affecting 70 million people worldwide [1]. Lifetime prevalence rate of epilepsy in developing countries is reported to be almost twice of that in the developed countries (10.4 vs 5.8 per 1000 population) [1]. Similar to developed countries in Saudi Arabia, the overall prevalence of epilepsy in 2001 was reported to be 6.54 per 1000 population (95\% confidence interval, 5.48 to 7.60) [2]. The same study reported the prevalence rate in Saudi adults older than 60 years of age to be 5.56 per 1000 population.

Epilepsy is a complex condition which tends to be subject to delays in diagnosis as the 
symptoms the patients display may not be always associated with textbook clinical symptoms [3]. This is even more complicated when it comes to older adults as this population is particularly exposed to atypical clinical manifestations [4]. As brain function changes with age, epilepsy episodes become less frequent and may be complicated with uncommon symptoms such as memory loss [5]. Age is a known risk factor for epilepsy with reported annual incidence rate of 10.8/1000 patients in patients older than 65 years $[6,7]$. The etiology of new onset epilepsy among older adults is usually linked to unknown causes [5]. Other causes could be related to cerebrovascular disease or neurodegenerative diseases (e.g., Alzheimer's) [5,7].

The management of epilepsy in older adults is highly challenging due to a multitude of factors. Drug-related factors that change with age include efficacy, pharmacokinetics, co-medications and medication side effect profiles $[4,8]$. Indeed, the medication regimen in the geriatric population is often complicated by three main challenges; namely, heightened sensitization to drug action, reduction in physiological elimination function and poly-pharmacy which may lead to drug-drug interactions or reduced drug absorption [9]. All these factors contribute to the increased prevalence of adverse events among the elderly, which is reported to be as high as $30 \%$ [9].

As opposed to drug serum level monitoring, it is now standard to monitor antiepileptic drugs (AEDs) using clinical assessment of seizure and incidence of adverse events [10]. As adverse effect reporting relies greatly on patient reported measures, the best way is to use systemic standardized patient reported measures for AED related symptoms [11]. The Liverpool adverse events profile (LAEP) was developed to assess adverse effects of AEDs [10]. The scale presents several items common with AEDs as a checklist of symptoms reported in the last 4 weeks rated on Likert scale responses. It is composed of 19 questions. The LAEP makes it possible for clinician to capture subjective symptoms reported by the patient in a measurable way [10]. LAEP was developed and validated back in 1994 among English speaking patients with epilepsy in the United Kingdom [12]. However, it was later translated and validated in different countries and languages [13-17]. Although LAEP has been translated and validated for use in some nonEnglish speaking populations [13-17], to our knowledge, there are no studies reporting the use of LAEP in Arab populations. The aim of this study was to translate, validate and use LAEP in the geriatric population with epilepsy in Saudi Arabia.

\section{METHODS}

\section{Instrument and measurement}

LAEP is a 19-item self-reported questionnaire, designed to measure the frequency of AEDs side effects experienced by epileptic patients within the past 4 weeks. LAEP covers both CNS and non-CNS related adverse effects, scored on 4point Likert scale as follows: 1 (always a problem), 2 (rarely a problem), 3 (sometimes a problem) and 4 (never a problem). The total scores range from 19 to 76 ; scores $\leq 45$ indicates mild to moderate adverse effects, and reaches the toxic level if the total score exceeds 45 [18-20].

\section{LAEP translation and validation}

The LAEP was first forward translated by a bilingual healthcare professional whose native language is Arabic. The Arabic version of LAEP was then backward translated by another bilingual healthcare professional whose native language is English. No significant differences were found in the backward translated version and the original English version. The Arabic version of the LAEP was then reviewed by two health outcomes researchers and a neurologist for face and content validity. The final Arabic version of LAEP was then approved by all the research team after addressing all the comments. The reliability of LAEP was checked using the Cronbach's Alpha method. The international approved guidelines for translation, adaptation, and validation of self-reported screening instruments were adhered to in this study [21].

\section{Data collection}

A medical chart review was performed in the departments of neurology at two tertiary care centers in the city of Riyadh, Saudi Arabia. Patients were considered eligible for inclusion in the study if they were diagnosed with seizure disorders regardless of the seizure type, aged $\geq$ 60 years, cognitively able, and on a single AED. Eligible patients were then contacted by three healthcare professionals to get their consent for a telephone interview after explaining the study's objectives. Once the patients consented, they were interviewed. The interview included questions about patients' sociodemographic (e.g., age, gender and education), and clinical characteristics (e.g., type of seizures \& antiepileptic drug used) besides LAEP questions. 


\section{Ethical approval}

The study was approved by King Saud University College of Medicine and King Faisal Specialist Hospital and Research Center institutional review boards in Riyadh, Saudi Arabia. For ethical reasons, the data were code, and no patient identifiers were used. The study complied with the guidelines of Declaration of Helsinki (DOH) ethical standards for medical research [22].

\section{Statistical analysis}

Descriptive statistics were conducted using t-test and Chi-square test. Factor analysis was also conducted to explore the number of factors that can be extracted from the Arabic version of LAEP. Statistical significance was defined by $p<$ 0.05. All analyses were performed using a statistical software (SAS, version 9.2, SAS Institute Inc, Cary, NC, USA).

\section{RESULTS}

Out of 131 patients, who met the inclusion criteria and were contacted, 74 patients (56.5\%) consented to participate in the study and were interviewed. The mean age of participants was 68.9 years. Approximately, $50 \%$ of the participants were male and illiterate. Almost $26 \%$ of the participants experienced at least one seizure episode within the past 6 months, however, the majority were seizure free. About two-thirds of the participants had generalized seizures and the remaining had partial seizures. Most of the participants were on either carbamazepine (36.49\%) or levetiracetam (29.73 \%). Participants' characteristics are shown in Table 1.

The frequencies of the adverse AED effects based on LAEP are shown in Figure 1. Adverse effects that were reported as always or sometimes on the LAEP were as follows: Disturbed sleep (29.73 \%), upset stomach (25.67 $\%)$, aggressiveness (22.98\%), sleepiness (22.79 $\%)$, Memory problems $(20.27 \%)$, headache $(20.27 \%)$, nervousness (18.2\%), weight gain $(18.2 \%)$, hair loss $(17.57 \%)$, depression (17.57 $\%)$, restlessness $(16.22 \%)$, difficulty in concentration (16.22\%), unsteadiness (12.17 $\%)$, blurred vision (10.82 \%), trouble with mouth or gum $(10.81 \%)$, shaky hands (9.46\%), tiredness $(8.1 \%)$, skin problems $(6.75 \%)$, and dizziness $(5.4 \%)$. The mean scores of LAEP items are presented in Table 2. The overall mean score of LAEP was 28.9, ranging between 19 and 56.
Table 1: Sociodemographic and clinical characteristics of participants

\begin{tabular}{|c|c|}
\hline Characteristic & $\begin{array}{c}\text { Participants } \\
(n=74)\end{array}$ \\
\hline Age (yr) & $68.9 \pm 7.4$ \\
\hline \multicolumn{2}{|l|}{ Gender } \\
\hline Male & $38(51.35)$ \\
\hline Female & $36(48.65)$ \\
\hline \multicolumn{2}{|l|}{ Education } \\
\hline Illiterate & $37(50)$ \\
\hline Elementary school & $9(12.16)$ \\
\hline Intermediate school & $4(5.41)$ \\
\hline High school diploma & $8(10.81)$ \\
\hline Associate degree & $7(9.46)$ \\
\hline Bachelor degree or more & $9(12.16)$ \\
\hline $\begin{array}{l}\text { Experienced seizures in the } \\
\text { past } 6 \text { months }\end{array}$ & $19(25.68)$ \\
\hline \multicolumn{2}{|l|}{ Type of seizure } \\
\hline Generalized & $50(67.57)$ \\
\hline Partial & $24(32.43)$ \\
\hline \multicolumn{2}{|l|}{ Antiepileptic drug (AED) } \\
\hline Phenytoin & $12(16.22)$ \\
\hline Carbamazepine & $27(36.49)$ \\
\hline Valproic acid & $11(14.86)$ \\
\hline Lamotrigine & $1(1.35)$ \\
\hline Levetiracetam & $22(29.73)$ \\
\hline Topiramate & $1(1.35)$ \\
\hline
\end{tabular}

Table 2: Mean score of LAEP items

\begin{tabular}{|c|c|}
\hline Adverse effect & Mean \pm SD \\
\hline Unsteadiness & $1.5 \pm 0.8$ \\
\hline Tiredness & $1.3 \pm 0.7$ \\
\hline Restlessness & $1.5 \pm 1.0$ \\
\hline $\begin{array}{l}\text { Feelings of anger or aggression } \\
\text { to others }\end{array}$ & $1.7 \pm 1.0$ \\
\hline Nervousness and/or agitation & $1.6 \pm 0.9$ \\
\hline Headache & $1.6 \pm 0.9$ \\
\hline Hair loss & $1.5 \pm 0.9$ \\
\hline Problems with skin & $1.3 \pm 0.7$ \\
\hline Double or blurred vision & $1.4 \pm 0.8$ \\
\hline Upset stomach & $1.7 \pm 1.1$ \\
\hline Difficulty in concentrating & $1.5 \pm 1.0$ \\
\hline Trouble with mouth or gums & $1.3 \pm 0.8$ \\
\hline Shaky hands & $1.4 \pm 0.8$ \\
\hline Weight gain & $1.6 \pm 1.0$ \\
\hline Dizziness & $1.2 \pm 0.6$ \\
\hline Sleepiness & $1.8 \pm 1.2$ \\
\hline Depression & $1.5 \pm 1.0$ \\
\hline Memory problems & $1.6 \pm 1.0$ \\
\hline Overall score & $28.9 \pm 8.9$ \\
\hline
\end{tabular}

Using factor analysis, six factors were extracted using the eigenvalue cutoff point of $\geq 1$ (Figure 2). The factors were labelled as follows: (1) Psychomotor symptoms (dizziness, unsteadiness, headache, hair loss, and upset stomach); (2) Neuro-somatic symptoms(double or blurred vision, memory problems, problems with skin, 


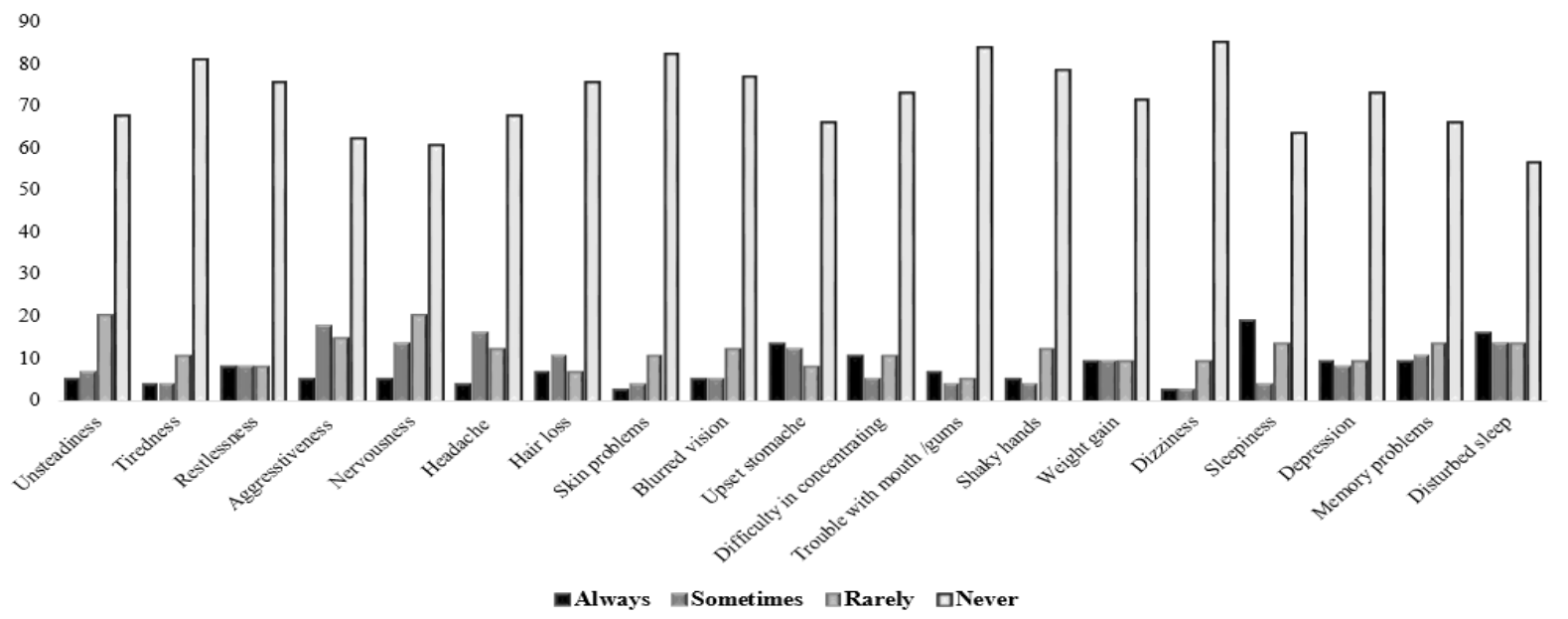

Figure 1: Frequency of AED adverse effects based on LAEP scale

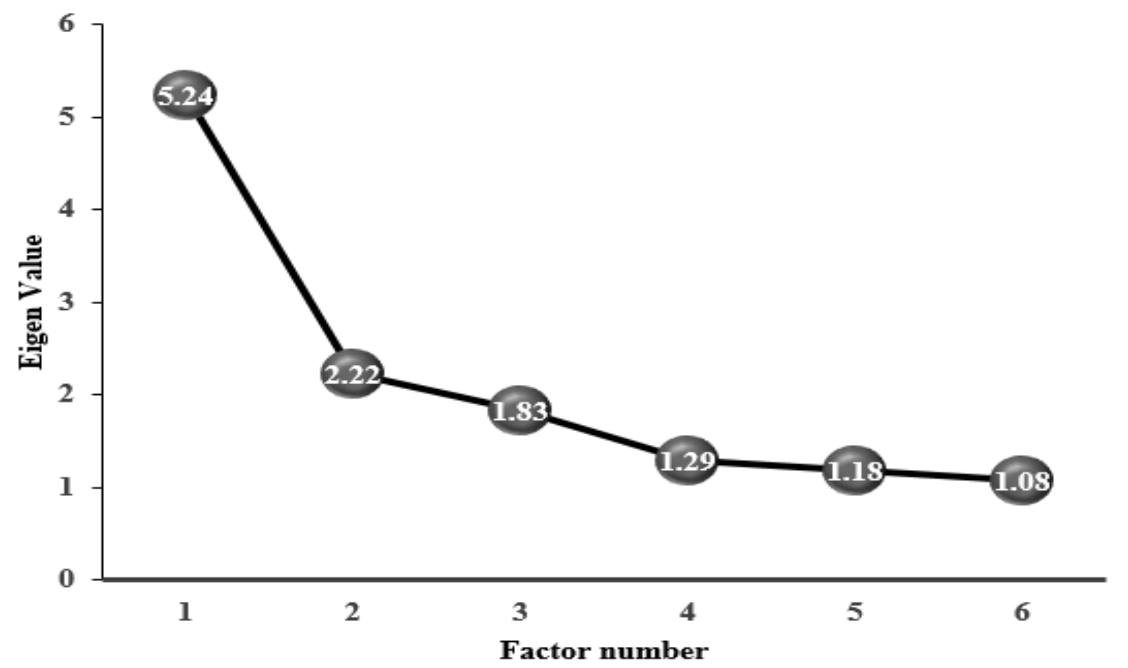

Figure 2: Scree plot of the number of factors that can be extracted from the Arabic version of LAEP and their Eigen values

and trouble with mouth or gums); (3) Behavioral symptoms (feelings of anger or aggression to others, and nervousness and/or agitation); (4) Mental disturbance symptoms (tiredness, disturbed sleep, depression, and restlessness) (5) Hypersomnia symptoms (weight gain and sleepiness); and (6) dementia-like symptoms (shaky hands and difficulty in concentrating). The Kaiser-Meyer-Olkin measure of sampling adequacy suggested that the study sample was factorable (KMO = 0.67). The internal consistency of the Arabic version of the LAEP was good (Cronbach's alpha $=0.84$ ). Table 3 shows the names of the extracted factors with their items, eigenvalues, and communalities.

\section{DISCUSSION}

For many decades, therapeutic drug monitoring (TDM) has been and still the cornerstone in optimizing the dosage regimen of AEDs in order to control seizures and minimize their side effects [22]. However, with the advent of the patientcentered care era, which has been taking root recently, healthcare researchers and providers alike are beginning to believe more in patient reported outcomes (PROs) [23]. Questionnaires and scales that measure patients' experiences with different treatment strategies including medications are gaining ground in clinical practice over the last two decades [24]. Questionnaires such as the LAEP that quantify patients' perceptions and experiences with medications in primary care are widely used nowadays [10-12]. In this study we aimed to translate and validate for the first time the LAEP in Arabic, which is a widely used questionnaire to quantify patients' experienced side effects with AEDs. However, we decided to focus on the geriatric patient population ( $\geq 60$ years) due to the fact that this segment of patients is largely ignored and faces tremendous problems with 
Table 2: Extracted factors from Arabic version of LAEP

\begin{tabular}{|c|c|c|c|c|c|c|c|}
\hline \multirow{2}{*}{ Adverse effect } & \multicolumn{6}{|c|}{$\begin{array}{ll}\text { Factors } \\
\end{array}$} & \multirow{2}{*}{$\begin{array}{c}\text { Communalities } \\
\text { (h2) }\end{array}$} \\
\hline & $\begin{array}{l}\text { Psycho-motor } \\
\text { symptoms }\end{array}$ & $\begin{array}{l}\text { Neuro-somatic } \\
\text { symptoms }\end{array}$ & $\begin{array}{l}\text { Behavioral } \\
\text { symptoms }\end{array}$ & $\begin{array}{c}\text { Mental } \\
\text { disturbance } \\
\text { symptoms }\end{array}$ & $\begin{array}{c}\text { Hypersomnia } \\
\text { symptoms }\end{array}$ & $\begin{array}{l}\text { Dementia-like } \\
\text { symptoms }\end{array}$ & \\
\hline Dizziness & 0.76 & & & & & & 0.67 \\
\hline Headache & 0.69 & & & & & & 0.62 \\
\hline Hair loss & 0.68 & & & & & & 0.58 \\
\hline Upset stomach & 0.67 & & & & & & 0.66 \\
\hline $\begin{array}{l}\text { Double or blurred } \\
\text { vision }\end{array}$ & & 0.79 & & & & & 0.74 \\
\hline Problems with skin & & 0.66 & & & & & 0.67 \\
\hline $\begin{array}{l}\text { Trouble with mouth or } \\
\text { gums }\end{array}$ & & 0.65 & & & & & 0.73 \\
\hline $\begin{array}{l}\text { nervousness and/or } \\
\text { agitation }\end{array}$ & & & 0.95 & & & & 0.93 \\
\hline $\begin{array}{l}\text { Feelings of anger or } \\
\text { aggression to others }\end{array}$ & & & 0.94 & & & & 0.94 \\
\hline Sleepiness & & & & & 0.75 & & 0.64 \\
\hline Shaky hands & & & & & & 0.87 & 0.81 \\
\hline $\begin{array}{l}\text { Difficulty in } \\
\text { concentrating }\end{array}$ & & & & & & 0.46 & 0.73 \\
\hline
\end{tabular}


medication adherence especially AEDs as well as in communication with healthcare providers [25]. Further, elderly patients may become more susceptible to the adverse effects of medications due to their diminished physical reserve [7-8].

Similar to previous studies, the Arabic version of the LAEP demonstrated good reliability (Cronbach's alpha $=0.84$ ) [13-17]. In addition, the face and content validity was checked by multiple healthcare professionals and deemed to be good. However, six factors were retained from the factor analysis that was performed to check the construct validity of the Arabic version of LAEP contrary to Baker et al and other validation studies that retained 3 factors only [13-17]. This could be explained by language differences and the fact that only elderly patients were included in the study.

In this study, the lowest and highest LAEP scores were 19 and 56, respectively. However, the mean LAEP score was 28.9, which is significantly lower than the ones reported in other studies, and suggests that the majority of patients in the study experienced low grade adverse AEDs effects [13-17]. This can be due to the fact that only patients on a single AED were included in the study as well as the tolerance to the AEDs adverse effects that patients might have developed over the years of treatment. Disturbed sleep, upset stomach, aggressiveness, sleepiness, memory problems and headache were the most commonly reported symptoms among more than $20 \%$ of the participants.

\section{Limitations of the study}

Although this study is the first to validate the LAEP in Arabic, it has several limitations. First, only patients on a single AED were included in the study. Second, the study was limited to elderly patients ( $\geq 60$ years) only. Third, the sample size of the study is small. Therefore, the results of this study have limited generalizability.

\section{CONCLUSION}

An Arabic version of LAEP has been has been established. It demonstrates good validity and reliability and makes it easier to screen Arabic speaking epileptic patients for common side effects of AEDs. Future studies should examine the validity and reliability of the Arabic version of LAEP among different epileptic patient populations.

\section{DECLARATIONS}

\section{Acknowledgement}

The authors acknowledge financial support from College of Pharmacy Research Center and Deanship of Scientific Research, King Saud University (Riyadh, Saudi Arabia).

\section{Conflict of Interest}

No conflict of interest associated with this work.

\section{Contribution of Authors}

The authors declare that this work was done by the authors named in this article and all liabilities pertaining to claims relating to the content of this article will be borne by them.

\section{Open Access}

This is an Open Access article that uses a funding model which does not charge readers or their institutions for access and distributed under the terms of the Creative Commons Attribution License (http://creativecommons.org/licenses/by/ 4.0) and the Budapest Open Access Initiative (http://www.budapestopenaccessinitiative.org/rea d), which permit unrestricted use, distribution, and reproduction in any medium, provided the original work is properly credited.

\section{REFERENCES}

1. Ngugi AK, Bottomley C, Kleinschmidt I, Sander JW, Newton CR. Estimation of the burden of active and lifetime epilepsy: A meta-analytic approach. Epilepsia. 2010; 51(5): 883-890.

2. Al Rajeh S, Awada A, Bademosi O, Ogunniyi A. The prevalence of epilepsy and other seizure disorders in an Arab population: a community-based study. Seizure. 2001; 10(6): 410-414.

3. D'Ambrosio R, Miller JW. What Is an Epileptic Seizure? Unifying Definitions in Clinical Practice and Animal Research to Develop Novel Treatments. Epilepsy Curr. 2010; 10(3): 61-66.

4. French JA, Staley BA. AED treatment through different ages: as our brains change, should our drug choices also? Epilepsy Curr.2012; 12(3): 22-27.

5. Arain AM, Abou-Khalil B. Management of new-onset epilepsy in the elderly. Nat Rev Neurol. 2009; 5(7): 363371.

6. Faught E, Richman J, Martin R, Funkhouser E, Foushee $R$, Kratt $P, \operatorname{Kim} Y$, Clements $K$, Cohen $N$, Adoboe $D$, Knowlton $R$, Pisu $M$. Incidence and prevalence of 
epilepsy among older US Medicare beneficiaries. Neurology. 2012; 78(7): 448-453.

7. Hauser WA. Seizure disorders: the changes with age. Epilepsia. 1992; 33: 6-14.

8. Willmore LJ. The effect of age on pharmacokinetics of antiepileptic drugs. Epilepsia. 1995; 36 Suppl.5: S14S21.

9. Gomez-Pavon J, Gonzalez Garcia P, Frances Roman I. Recommendations for the prevention of adverse drug reactions in older adults with dementia. Rev Esp Geriatr Gerontol. 2010; 45: 89-96.

10. Panelli RJ, Kilpatrick C, Moore SM, Matkovic Z, D'Souza WJ, O'Brien TJ. The Liverpool adverse events profile: relation to AED use and mood. Epilepsia. 2007; 48(3): 456-463.

11. Baker GA, Camfield C, Camfield P, Cramer JA, Elger CE, Johnson AL, Martins da Silva A, Meinardi H, Munari C, Perucca E, Thorbeke R. Commission on outcome measurement in epilepsy, 1994-1997: final report. Epilepsia. 1998; 39(2): 213-231.

12. Baker GA, Frances $P$, Middleton $E$, Jacoby A, Schaper GJ, Defalla B, Young C, Smith DF, Chadwick DW. Initial development, reliability, and validity of a patient based adverse event scale. Epilepsia. 1994; 35(Suppl 7): 80.

13. Martins HH, Alonso NB, Vidal-Dourado M, Carbonel TD, de Araújo Filho GM, Caboclo LO, Yacubian EM, Guilhoto LM. Are adverse effects of antiepileptic drugs different in symptomatic partial and idiopathic generalized epilepsies? The Portuguese-Brazilian validation of the Liverpool Adverse Events Profile. Epilepsy \& Behav. 2011; 22(3): 511-517.

14. Carreno M, Donaire A, Falip M, Maestro I, Fernandez S, Nagel AG, Serratosa J, Salas J, Viteri C, Liorens J, et al. Validation of the Spanish version of the Liverpool Adverse Events Profile in patients with epilepsy. Epilepsy Behav. 2009; 15(2): 154-159.

15. Chen HF, Tsai YF, Shih MS, Chen JC. Validation of the Chinese version of the Liverpool Adverse Events Profile in patients with epilepsy. Epilepsy Res. 2011; 94(1-2): 45-52.

16. Kuzmanova R, Stefanova I, Velcheva I, Stambolieva K. Translation, cross-cultural adaptation, and validation of the Bulgarian version of the Liverpool Adverse Event Profile. Epilepsy Behav.2014; 39: 88-91.

17. Park JM, Seo JG, Park SP. Validity and reliability of the Korean version of the Liverpool Adverse Events Profile $(K-L A E P)$ in people with epilepsy. J Korean Epilepsy Soc. 2012; 16(2): 43-48.

18. Andrew T, Milinis K, Baker G, Wieshmann U. Selfreported adverse effects of mono and polytherapy for epilepsy. Seizure. 2012; 21(8): 610-613.

19. Baker GA, Jacoby $A$, Francis $P$, Chadwick DW. The Liverpool adverse drug events profile. Epilepsia. 1995; 36(suppl.3): 559.

20. Gilliam FG, Fessler AJ, Baker G, Vahle V, Carter J, Attarian $H$. Systematic screening allows reduction of adverse antiepileptic drug effects: a randomized trial. Neurology. 2004; 62(1): 23-27.

21. Sousa, VD, Rojjanasrirat $W$. Translation, adaptation and validation of instruments or scales for use in cross-cultural health care research: a clear and user-friendly guideline. J Eval Clin Pract. 2011; 17(2): 268-274.

22. World Medical Association. World Medical Association Declaration of Helsinki: ethical principles for medical research involving human subjects. Bull World Health Organ. 2001;79(4):373-374.

23. Patsalos PN, Berry DJ, Bourgeois BF, Cloyd JC, Glauser TA, Johannessen SI, Leppik IE, Tomson T, Perucca E. Antiepileptic drugs-best practice guidelines for therapeutic drug monitoring: a position paper by the subcommission on therapeutic drug monitoring, ILAE Commission on Therapeutic Strategies. Epilepsia. 2008; 49(7): 1239-1276.

24. Weaver RR. Reconciling evidence-based medicine and patient-centred care: defining evidence-based inputs to patient-centred decisions. J Eval Clin Pract. 2015; 21(6): 1076-1080.

25. Deshpande PR, Rajan S, Sudeepthi BL, Abdul Nazir CP. Patient-reported outcomes: $A$ new era in clinical research. Perspect Clin Res. 2011; 2(4): 137-144.

26. Yap AF, Thirumoorthy T, Kwan YH. Systematic review of the barriers affecting medication adherence in older adults. Geriatr Gerontol Int. 2016; 16(10): 1093-1101. 